Int. J. Electrochem. Sci., 12 (2017) $4193-4203$

\title{
Identification of Two Positional Isomers between Ortho-Vanillin and Para-Vanillin by their Inhibitory Effects on a Briggs- Rauscher Oscillator
}

\author{
Waqar Uddin ${ }^{1}$, Gang $\mathrm{Hu}^{1, *}$, Lin $\mathrm{Hu}^{2}$, Yanyang $\mathrm{Hu}^{3}$, Zhaohui $\mathrm{Fang}^{4}$, Saif Ullah ${ }^{1}$, Xuanxuan Sun ${ }^{1}$, \\ Xiaofeng Shen ${ }^{1}$, and Jimei Song ${ }^{1}$ \\ ${ }^{1}$ Department of Chemistry, Anhui University, Hefei, 230601, People's Republic of China \\ ${ }^{2}$ Institute of Applied Chemistry, East China Jiaotong University, Nanchang, 330013, People's \\ Republic of China \\ ${ }^{3}$ Department of Chemistry, Purdue University, West Lafayette, IN, 47907, U.S.A \\ ${ }^{4}$ The First Affiliated Hospital of Anhui University of Chinese Medicine, Hefei, 230031, People's \\ Republic of China \\ *E-mail: hugang@ustc.edu
}

doi: $10.20964 / 2017.05 .13$

Received: 28 January 2017 / Accepted: 4 March 2017 / Published: 12 April 2017

\begin{abstract}
A suitable method by means of Briggs-Rauscher (BR) oscillating system as an analytical technique to identify the two positional isomers between ortho-vanillin (OV) and (para-)vanillin (PV) by their different perturbation effects has been proposed in this article. In BR system the macrocyclic $\mathrm{Ni}$ complex, [NiL] $\left(\mathrm{ClO}_{4}\right)_{2}$ was used as catalyst, in which ligand $\mathrm{L}$ is 5,7,7,12,14,14-hexamethyl-1,4,8,11tetraazacyclotetradeca-4,11-diene. The experimental data has proven that putting equal amount of same concentrations of these isomers (OV and PV) separately into the active BR system could cause the inhibition time $\left(t_{i n}\right)$. But the $t_{\text {in }}$ initiated by OV is higher as compared to the $t_{\text {in }}$ produced by PV. Our predication for such different inhibitory effects caused by these isomers may be due to their different existing strength of intermolecular hydrogen-bonding. Furthermore, by plotting $t_{\text {in }}$ against the concentration of $\mathrm{OV}$ or $\mathrm{PV}$, two linear regression curves were achieved for these two isomers in their concentrations range $2.5 \times 10^{-6} \mathrm{~mol} \mathrm{~L}^{-1}$ to $4 \times 10^{-5} \mathrm{~mol} \mathrm{~L}^{-1}$ with correlation coefficients of 0.98 , which obviously illustrated the different behaviors of isomers. The perturbation reaction mechanism, involving hydroperoxyl radical (HOO${ }^{\circ}$ ) on the basis of FCA has been proposed. The description of the proposed mechanism is that these isomers react with hydroperoxyl radical to form a dimeric product (divanillin).
\end{abstract}

Keywords: Briggs-Rauscher Oscillator; Inhibition time; Isomers Identification; Ortho Vanillin; Para Vanillin

\section{FULL TEXT}


(C) 2017 The Authors. Published by ESG (www.electrochemsci.org). This article is an open access article distributed under the terms and conditions of the Creative Commons Attribution license (http://creativecommons.org/licenses/by/4.0/). 